\title{
Strategies for public health initiatives targeting dairy consumption in young children: a qualitative formative investigation of parent perceptions
}

\author{
Mary E Jung ${ }^{1, *}$, Jessica E Bourne ${ }^{1}$, Andrea Buchholz ${ }^{2}$ and Kathleen A Martin Ginis ${ }^{1}$ \\ 'School of Health and Exercise Sciences, University of British Columbia, 1147 Research Road, ART-360, Faculty of \\ Health and Social Development, Kelowna, British Columbia, Canada, V1V 1V7: ${ }^{2}$ Department of Family Relations \& \\ Applied Nutrition, Guelph University, Guelph, Ontario, Canada
}

Submitted 10 February 2017: Final revision received 23 June 2017: Accepted 3 July 2017: First published online 30 August 2017

\begin{abstract}
Objective: Dairy products contain essential nutrients to ensure healthy growth and bone development in children. However, a significant proportion of children in developed countries fail to consume the daily recommended intake of dairy products. Parents are the gatekeepers of familial nutritional intake and represent a potential vehicle through which to increase dairy consumption in children. As such, formative research was conducted to gain insight into parents' perceived barriers to and benefits of purchasing and consuming dairy products and to develop innovative message content that could be utilized in future public health campaigns.

Design: Seven in-depth group interviews were conducted in two phases between February and May 2015.

Setting: Interviews were conducted in local recreational centres and libraries in British Columbia, Canada.

Subjects: Mothers ( $n$ 21, mean age 38 (sD 5) years) and fathers ( $n$ ), mean age 38 (SD 3) years) of children aged 4-10 years.

Results: Parents perceived both positive and negative physical outcomes associated with consuming dairy. Lack of trustworthy information was a frequently discussed barrier theme to purchasing and consuming dairy products. Mothers were concerned about the cost of dairy products. Differences in purchasing and consumption strategies were reported between parents of children who consumed adequate dairy and those who did not. Parents believed the most appropriate communication channel was through print material.

Conclusions: Messages targeting parents, as a means of increasing dairy consumption in children, should address barriers identified by parents. In addition, practical tips should be provided to promote purchasing and consumption of dairy products.
\end{abstract}

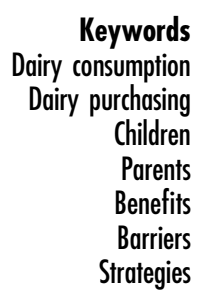

Dairy products provide children with essential macro- and micronutrients ${ }^{(1)}$, and are unique in that they offer a high concentration of readily absorbable dietary $\mathrm{Ca}^{(2,3)}$, essential for maximizing growth and peak bone mass in children. Inadequate consumption of $\mathrm{Ca}$ during this time can lead to lifelong health problems including an increased risk of fractures and osteoporosis ${ }^{(4,5)}$. Despite these benefits, the most recent Canadian national survey ${ }^{(6)}$ indicates that $37 \%$ of children between 4 and 9 years of age fail to consume the recommended daily number of dairy servings ( $\geq 2$ for children aged $4-8$ years; $\geq 3$ for children aged 9-10 years $\left.{ }^{(7)}\right)$. A similar pattern of underconsumption is seen in other developed countries including the $\mathrm{USA}^{(8)}$ and Australia ${ }^{(9)}$. Given the potential negative outcomes associated with inadequate dairy intake and the low rates of consumption among children, it is imperative that effective intervention strategies be determined for this population.

A systematic review by Hendrie et $a$. $^{(10)}$ identified fourteen interventions aimed at increasing dairy or $\mathrm{Ca}$ consumption in children discretely ( $n 5$ ), in the context of a healthy diet $(n 8)$ or as part of a combined nutrition and physical activity intervention ( $n$ 6). Ten of these interventions were classified as effective, operationalized as a statistically significant increase in a dairy outcome measured either objectively (e.g. observed intake) or using 
dietary assessment methods (e.g. an FFQ). However, six of these effective interventions increased Ca or dairy intake through the provision of dairy products free of charge as an intervention strategy. While initially effective, providing families with free dairy products does not represent a sustainable method of promoting volitional intake, nor is it a feasible strategy to reach a large number of individuals.

Parents have been highlighted as a potential channel through which to positively impact the nutritional behaviour of children. Coined the 'nutritional gatekeepers', Wansink ${ }^{(11)}$ estimated that parents control $72 \%$ of the food eaten by their young children. This is not surprising given that parents typically control what food is purchased for the family and what meals are prepared for consumption within and outside the home. In addition, parents play a pivotal role in children's diet through modelling. It is well known that young children learn through observation and emulation of the behaviours of their parents, especially with regard to eating habits. Cooke et al. ${ }^{(12)}$ reported that parents' fruit and vegetable consumption was a significant predictor of a child's intake of those foods. In relation to dairy, Fisher et al. ${ }^{(13)}$ demonstrated that when mothers drank and served milk frequently in front of their young girls (aged 5-9 years), the girls were more likely to meet the recommended daily intake of $\mathrm{Ca}$. Parental role modelling has been shown to be a more successful method of improving a child's dietary consumption compared with more controlling tactics, such as restricting access to certain foods ${ }^{(14)}$. Therefore, the direct inclusion of parents in dairy promotion interventions may present a feasible strategy through which to both increase household purchasing of dairy and promote children's dairy consumption $^{(10,15)}$.

In the context of promoting a healthy diet, Hendrie et $a l{ }^{(10)}$ identified three studies that incorporated parents in the intervention design. Specifically, Evans et al. ${ }^{(16)}$ focused on parents' provision of packed lunches and reported a significant increase in dairy food consumption during school lunch. Despite this, only $60 \%$ of children consumed the recommended intake of one portion of dairy daily during school lunch, as measured 3 months after the intervention. The other two interventions involved providing parents and children with specific dietary guidelines in an aim to decrease children's $\mathrm{BMI}^{(17,18)}$. Both studies reported daily increases of approximately 0.3 servings of low-fat dairy foods immediately post the interventions that lasted between 2 and 3 years; no further follow-up statistics were reported. While these findings are positive, children were not consuming sufficient dairy to meet the daily recommended intakes following the interventions.

Interestingly, none of the interventions reported by Hendrie et $a l .{ }^{(10)}$ specifically targeted parents' attitudes or behaviour as a mechanism for changing their children's dairy consumption. Instead, parents were included as a complementary social influence within intervention designs that were primarily targeted towards children. Given the evidence surrounding the impact of role modelling it is possible that directly targeting parents' thoughts, feelings and behaviour towards dairy product purchasing and consumption could have a meaningful impact on increasing children's dairy consumption. In an intervention aimed at increasing fruit and vegetable consumption in pre-school children, Haire-Joshu et al. ${ }^{(19)}$ directly targeted parents' behaviour through education and emphasizing the importance of modelling fruit and vegetable consumption. Parents' knowledge regarding fruit and vegetable consumption, availability of fruits and vegetables in the home, and parents' consumption of fruits and vegetables all increased following the intervention. Most importantly, parents' change in fruit and vegetable intake was a significant predictor of children's change in fruit and vegetable consumption. To our knowledge, no studies have examined the impact of intervention material directly targeting parents' dairy-associated attitudes and behaviour as the primary method of increasing consumption of dairy products in children. This is important as positive changes to dietary intake during childhood, such as ensuring adequate dairy consumption, may track into adult dietary behaviours ${ }^{(20,21)}$.

A framework through which to develop targeted messages is Social Cognitive Theory ${ }^{(22)}$. Social Cognitive Theory posits that the decision to engage in a specific behaviour is influenced by three factors: (i) the outcomes expected to occur as a result of performing the behaviour (outcome expectations); (ii) the values placed on these outcomes (outcome values); and (iii) the individual's confidence to perform the behaviour in the face of setbacks (self-regulatory efficacy). In the context of dairy consumption, individuals are more likely to consume dairy products if they believe consumption will elicit personally valued outcomes (i.e. outcome expectations) and if they are confident that they can consume dairy regardless of any potential barriers (i.e. self-regulatory efficacy).

Previous research has demonstrated the effectiveness of targeted interventions based on Social Cognitive Theory in increasing volitional dairy consumption in young women $^{(23)}$ and adults aged $30-50$ years ${ }^{(24)}$. Targeted interventions involve the development of material specific to a subset of the population, rather than specific to each individual, and thus have the potential to reach large numbers of people within the targeted subset at a relatively low cost. In a qualitative investigation of dairy consumption in adults aged 30-50 years, Jung et al. ${ }^{(25)}$ found that compared with non-parents, parents had a unique set of attitudes and consumption strategies pertaining to dairy foods. Given the distinct social and environmental situations parents encounter, it is imperative to gather information related to dairy product purchasing and consumption as it relates specifically to parents in order to develop effective targeted intervention material. With this in mind, the overall purpose of the 
present formative research was to: (i) ascertain how social cognitions related to dairy product consumption, for both parent and child, and purchasing behaviour manifest in parents of children aged 4-10 years; and (ii) use this information to develop novel intervention messages, specifically targeted towards parents, that could positively impact these social cognitions and the subsequent behaviour of parent and child. The study focused on parents of children aged between 4 and 10 years as the influence of parents and the home food environment significantly influences children's dietary intake during this time $e^{(26,27)}$. As children get older their dietary intake will likely be influenced by additional factors such as school, peers and social media. Given that dairy intake during childhood can have an impact on adolescent bone health ${ }^{(28)}$, it is key to establish adequate intake behaviours during this influential time.

\section{Methods}

\section{Study design and procedure}

Formative research provides insight into characteristics of the target population that influence choices and actions to aid in the development of effective strategies through which to promote behaviour change. These strategies are then tested with the target audience. The current study consisted of two phases. In Phase I, the exploratory phase, in-depth group interviews were conducted with parents of children who consumed both above and below the recommended daily intake of dairy ${ }^{(7)}$ to learn about barriers and benefits that may influence parent purchasing and consumption of dairy products, to ascertain useful strategies to ensure the purchasing and consumption of dairy products and to explore effective channels of communication. Information gleaned from Phase I was used to guide the development of draft intervention messages. These draft messages were then tested through a second round of in-depth group interviews in Phase II, the elaborative phase. Parents of children who failed to consume the recommended intake of dairy were the focus of Phase II as they represent the target group for future intervention. In-depth group interviews were considered appropriate to enable participants to generate and share ideas, encouraging dynamic and unique discussion ${ }^{(29)}$. The study was conducted according to the guidelines in the Declaration of Helsinki and all procedures were approved by the University of British Columbia Behavioural Ethics Committee. Written informed consent was obtained from all participants. A total of thirty participants took part in seven in-depth group interviews conducted across the two phases, specifically four in-depth interviews in Phase I and three in Phase II. Data collection ceased when no new categories emerged from the data (i.e. data saturation had been reached). All participants were recruited through online advertisements, word of mouth and posters placed in the local urban community. Phase I took place in February 2015 and Phase II in May 2015, all within the local community. A researcher experienced in moderating in-depth group interviews facilitated each group interview in the current study, while a trained research assistant took field notes to capture any non-verbal communication and group dynamics. A debrief occurred after each interview with research staff to reflexively guide future interviews. Each group interview lasted approximately $1.5 \mathrm{~h}$. All group interviews were audio-taped and transcribed verbatim.

\section{Phase I: exploratory group interviews}

Two researchers with knowledge of behaviour change theories pertinent for dietary behaviour and qualitative methodology developed the semi-structured group interview guide. Questions and activities were designed to enable group discussion around barriers to and benefits of the target behaviour, and were intended to be interactive in nature. The interview guide consisted of four sections: (i) an introductory section pertaining to participants' dairy product purchasing and consumption habits; (ii) questions exploring participants' perceived anticipated outcomes from purchasing and consuming dairy products for themselves and their children; (iii) brainstorming activities to elicit strategies for ensuring the purchase and consumption of dairy products for parents and their children; and (iv) questions exploring preferred information delivery methods and format (see the online supplementary material for the interview guide). A brief demographic survey was administered at the beginning of each focus group. At the end of the interviews, participants were given the opportunity to raise any topics they felt had been missed and were important in relation to their families' purchasing and consumption of dairy products.

Forty-one individuals contacted the research team to take part in the study and were screened for study eligibility. Eligibility criteria included men and women (i) with a child between 4 and 10 years of age, (ii) who had no dietary constraints for consuming dairy products themselves, (iii) whose child had no dietary constraints for consuming dairy products (e.g. vegetarian, vegan, paleo or dairy allergies) and (iv) who were able to read and write English. Individuals self-identified their gender, and their child's dairy consumption was established using a modified version of the 'Calcium Calculator ${ }^{\mathrm{TM}}$ ' developed by the British Columbia Dairy Foundation ${ }^{(30)}$. The original tool assessed consumption of $\mathrm{Ca}$ from a comprehensive list of thirty commonly consumed dairy and non-dairy foods that are available in Canada and has been found to be a valid assessment of dietary $\mathrm{Ca}$ intake ${ }^{(31)}$. In the current study, parents were asked to indicate the number of servings of the ten dairy products included in the list that their child consumed on the previous day. A serving size was explained for each product. The ten-item version of this tool has been used in previous studies to assess Ca consumption ${ }^{(21)}$. 
Participants were then stratified into groups according to their self-identified gender and their child's dairy consumption status. Dairy consumption status was classified as either meeting Canada's daily dairy consumption guidelines ( $\geq 2$ servings/d for children $4-8$ years, $\geq 3$ servings/d for children 9-10 years) or not meeting Canada's daily dairy consumption guidelines ( $<2$ servings/ d for $4-8$ years, $<3$ servings/d for 9-10 years). Eighteen individuals were eligible and able to attend the meeting time. Participants were mothers ( $n$ 11, mean age 37 (SD 7 ) years) and fathers ( $n 7$, mean age 38 (SD 5) years) of children who were classified as under-consumers of dairy ( $n$ 10) or adequate consumers ( $n$ 8). One group interview was held with each stratified group. The majority of participants identified as exclusively white $(77 \cdot 8 \%)$, married (66.7\%), had at least a college or other non-university certificate $(94.5 \%)$, worked full- or part-time (66.7\%) and had two or more children in the household (66.6\%). Participants made food purchasing decisions for the household either themselves $(44.4 \%)$ or in collaboration with their partner $(50.0 \%)$ and did the grocery shopping either themselves $(38.9 \%)$ or with their partner (44.4\%).

\section{Phase II: elaborative group interviews}

A second round of in-depth group interviews were conducted with a new group of participants to (i) further probe and discuss the findings drawn from the exploratory group interviews to ensure that data saturation had occurred and (ii) pre-test a series of draft messages developed from the information gleaned from Phase I. Participants were asked to provide feedback on message content relevance and the appropriateness of proposed delivery methods. Phase II was conducted with a new group of participants to confirm the findings revealed in Phase I and to test the draft messages exclusively with the target audience (i.e. parents of children failing to meet the recommended intake of dairy).

Fourteen individuals contacted the research team and were screened for eligibility. Eligibility criteria were the same as in Phase I, with the addition that children must be consuming less than the recommended intake of dairy. A total of twelve participants were eligible and able to attend the meeting times. These individuals were stratified into groups based on self-identified gender (mothers: $n$ 10, mean age 38 (SD 3) years; fathers: $n 2$, mean age 37 (SD 1) years). Demographic characteristics for Phase II participants were similar to those of Phase I (see Table 1).

\section{Analyses}

Given the interaction between the study objectives and our data, an abductive approach to data analysis was taken $^{(29)}$. Using the interview guide as a framework, deductive content-based analysis was conducted in order to organize initial coding categories (e.g. barriers; benefits; strategies). Thematic analysis was then carried out to inductively explore recurring patterns within these categories. Content was further delineated into sub-themes with similar content. For information that could not be coded using the original categories, new categories were developed for important information related to the purchasing and consumption of dairy products. Data were imported into NVivo qualitative analysis software version 11 (2015; QSR International Pty, Ltd) where each transcript was analysed independently by two researchers. Once complete, the two researchers met to compare and discuss coding and categorization. Agreement rates of 90 and $91 \%$ were reported for Phase I and II, respectively. Disagreements in coding were discussed and resolved through consensus. Results across group interviews were used to guide the development of potential intervention messages.

\section{Message development}

Information gleaned from Phase I in-depth group interviews was used to create a series of draft intervention messages. Specifically, following completion of Phase I data analyses three members of the research team engaged in a series of four brainstorming and development sessions, one each for benefits, barriers, consumption strategies for parent and child, and purchasing strategies. During these sessions, the researchers discussed the most appropriate method of delivering these messages based on the Phase I findings. The outcome of the sessions was a series of draft messages, and proposed delivery methods, to be delivered to participants in Phase II of the study for review. Participants in Phase II were asked to state (i) whether they would find the message content useful and (ii) if they would pay attention to the message. Feedback from the draft messages presented in Phase II was used to create the final intervention messages, and delivery methods, in collaboration with two behaviour change experts and a registered dietitian.

\section{Results}

Themes are presented for each of the initial coding categories, namely benefits, barriers, purchasing strategies, consumption strategies and communication methods. There was significant overlap in responses from participants from the two phases of interviews. The results are reported combining the responses from both phases, unless patterns emerged that were specific to one phase, in which case this is specified. Differences between (i) mothers and fathers and (ii) parents of children who met the recommended intake of dairy and parents of those who did not are reported where applicable. Subsequent message development is reported.

\section{Benefits}

\section{Convenience}

All mothers of children who consumed above and below the recommended intake of dairy perceived dairy 
Table 1 Demographic statistics for Phase I and Phase II participants independently and for the whole sample, British Columbia, Canada, February-May 2015

\begin{tabular}{|c|c|c|c|c|c|c|c|c|c|c|c|c|}
\hline & \multicolumn{4}{|c|}{ Phase I (exploratory) } & \multicolumn{4}{|c|}{ Phase II (elaborative) } & \multicolumn{4}{|c|}{ Total sample } \\
\hline & $n$ & $\%$ & Mean & SD & $n$ & $\%$ & Mean & SD & $n$ & $\%$ & Mean & SD \\
\hline \multicolumn{13}{|l|}{ Gender } \\
\hline Fathers & 7 & 38.9 & 38 & 5 & 2 & $16 \cdot 7$ & 37 & 1 & 9 & $30 \cdot 0$ & 38 & 4 \\
\hline Mothers & 11 & $61 \cdot 1$ & 37 & 7 & 10 & 83.3 & 38 & 3 & 21 & $70 \cdot 0$ & 38 & 5 \\
\hline \multicolumn{13}{|l|}{ Ethnic origin } \\
\hline White & 14 & $77 \cdot 8$ & & & 11 & $91 \cdot 7$ & & & 25 & 83.3 & & \\
\hline White and Aboriginal & 3 & $16 \cdot 7$ & & & & & & & 3 & $10 \cdot 0$ & & \\
\hline White and Latin American & 1 & $5 \cdot 6$ & & & 1 & $8 \cdot 3$ & & & 2 & $6 \cdot 7$ & & \\
\hline \multicolumn{13}{|l|}{ Education } \\
\hline High school or less & 1 & $5 \cdot 6$ & & & 1 & $8 \cdot 3$ & & & 2 & $6 \cdot 7$ & & \\
\hline $\begin{array}{l}\text { College, CEGEP or other non-university } \\
\text { certificate or diploma }\end{array}$ & 5 & $27 \cdot 8$ & & & 5 & $41 \cdot 7$ & & & 10 & 33.3 & & \\
\hline University certificate, diploma or degree & 10 & $55 \cdot 6$ & & & 2 & $16 \cdot 7$ & & & 12 & $40 \cdot 0$ & & \\
\hline Postgraduate degree & 2 & $11 \cdot 1$ & & & 4 & 33.3 & & & 6 & $20 \cdot 0$ & & \\
\hline \multicolumn{13}{|l|}{ Marital status } \\
\hline Single & 4 & $22 \cdot 2$ & & & & & & & 4 & $13 \cdot 3$ & & \\
\hline Married & 12 & 66.7 & & & 12 & $100 \cdot 0$ & & & 24 & 80.0 & & \\
\hline Separated/divorced & 2 & $11 \cdot 1$ & & & & & & & 2 & 6.7 & & \\
\hline \multicolumn{13}{|l|}{ Employment status } \\
\hline Full-time & 9 & 50 & & & 5 & 41.7 & & & 14 & $46 \cdot 7$ & & \\
\hline Part-time/occasional work & 3 & $16 \cdot 7$ & & & 6 & $50 \cdot 0$ & & & 9 & $30 \cdot 0$ & & \\
\hline Student & 2 & 11.1 & & & 1 & $8 \cdot 3$ & & & 3 & $10 \cdot 0$ & & \\
\hline Stay-at-home mum & 4 & $22 \cdot 2$ & & & & & & & 4 & $13 \cdot 3$ & & \\
\hline \multicolumn{13}{|l|}{ Annual household income (\$CAN) } \\
\hline $25000-50000$ & 8 & $47 \cdot 1$ & & & 1 & $8 \cdot 3$ & & & 9 & 31.0 & & \\
\hline $50000-100000$ & 4 & 23.5 & & & 5 & $41 \cdot 6$ & & & 9 & $31 \cdot 0$ & & \\
\hline$\geq 100000$ & 5 & 29.4 & & & 6 & 49.9 & & & 11 & 38.0 & & \\
\hline \multicolumn{13}{|l|}{ Number of children/dependants in house } \\
\hline (1) & 6 & 33.3 & & & 6 & $50 \cdot 0$ & & & 12 & $40 \cdot 0$ & & \\
\hline 2 & 8 & 44.4 & & & 4 & 33.3 & & & 12 & $40 \cdot 0$ & & \\
\hline$\geq 3$ & 4 & $22 \cdot 2$ & & & 2 & $16 \cdot 7$ & & & 6 & 20.0 & & \\
\hline
\end{tabular}

CEGEP, general and vocational college.

products as convenient for children to consume at home or school and they could be purchased in a manner that allowed children to open and consume the product independently. One mother reported:

'Part of it is convenience. Like I give my kids these Nano's [yoghurt tubes] at lot. It's easy for them to open and recycle and it's just the right amount to give them a shot of energy at snack time.'

Taste

All parents (henceforward, 'all parents' refers to parents of children who consumed both above and below the recommended intake of dairy) discussed the enjoyable taste of dairy products as a benefit of consumption for both themselves and their children. Parents took comfort in knowing their children enjoyed eating dairy products, with one parent stating:

'At school she'll have a cheese stick, and she loves cheese.'

Cheese was the most frequently discussed dairy product regarding taste.

\section{Overall health}

Dairy products were believed to increase overall energy and aid in recovery from physical activity by all parents. As reported by one parent:

'I remember many times that the best thing to have after you have a workout is chocolate milk. My daughter is very physically active, so I think that that helps her keep her energy up.'

In addition, all parents mentioned that dairy products were part of a well-balanced diet, contributing to overall health.

\section{Nutritional content}

All parents described the primary benefit of consuming dairy products as being their high nutritional content. Specifically, parents believed that dairy products were a good source of $\mathrm{Ca}$, protein and vitamin $\mathrm{D}$, aiding with bone development in children and bone maintenance in adults. For example, when discussing consuming dairy products one parent stated:

'For my son, sometimes in the morning he doesn't have a big appetite. So being able to get a big amount of milk and yoghurt into him is good 
because I know it has a good amount of protein and fat. Rather than just a piece of toast and that's it, so I'd rather he just have that.'

All parents expressed a desire for information about how the nutritional content of dairy products compared directly with non-dairy products.

Based on these findings, message content was created that focused on providing nutritional comparisons between dairy and non-dairy products for participants to assess the benefits of dairy intake. In addition, messages highlighted the role of dairy products for maintaining overall health and emphasized the convenience of dairy products. Participants in the elaborative phase expressed a desire for messages to contain even more information pertaining to the nutritional content of dairy products, specifically $\mathrm{Ca}$ and protein.

\section{Barriers}

\section{Negative health outcomes}

All parents expressed concerns that dairy products were high in fat and sugar and that consuming these products could negatively impact their weight control. In addition, all parents highlighted physical sensitivity including excess gas, diarrhoea, mucus, eczema and low energy as frequent outcomes of dairy consumption for both themselves and/ or their child. One parent commented:

'He's [child] also very phlegmy, I feel like he has a cold a lot, so the more milk he drinks, the worse it is'.

\section{Excessive packaging and processing}

For all mothers, the packaging of dairy products was a barrier to purchasing, with one mother stating:

'I can't stand these things [yoghurt tubes]. I can't stand the waste of them.'

In addition, all mothers felt that there were a lot of artificial additives in many dairy products.

\section{Contamination of dairy products}

Concerns regarding the contamination of dairy products was a commonly discussed barrier to dairy product purchasing and consumption for all parents, with one parent stating:

'I believe that pasteurizing is a big part of the problem, it's contributing to people having sensitivities, as well as the hormones and antibiotics.'

All parents believed that regular dairy products contained hormones and antibiotics and as a result felt that buying organic products was preferable:

'Who knows what's going on so it's better to just stick with the organic and not have to worry about it.'
Cost

Due to contamination concerns, all mothers and fathers of children who consumed above the recommended intake of dairy felt they should purchase organic dairy products. However, the cost of these products was a concern:

'That's a barrier for me is what is in dairy products that are just mainstream dairy products versus organic dairy products and can I afford organic?'

The cost of dairy products in general was also a concern and appeared to be a greater concern for all mothers as compared with fathers.

\section{Lack of trustworthy information}

All parents expressed feelings of confusion regarding the health benefits and contents of dairy products, which inhibited their purchasing and consumption. Parents discussed feeling overwhelmed by the amount of information and mistrusting the sources of much of this information. For example, one parent commented:

'I think the whole thing's just a little fishy [milk production]. So I'd rather stay away.'

Another participant questioned the trustworthiness of the grocery stores selling the products:

"When you see it at the grocery store you have your doubts too because you see them at the grocery store, like at superstore, is it really that organic?'

Parents in the elaborative phase shared that despite a feeling of information saturation they desired more information pertaining to ethical and contamination issues, nutritional content and expected outcomes of dairy consumption from unbiased, trustworthy sources, in order to provide clarity. Reputable sources of information included Health Canada, local health authorities, schools, universities and health-care professionals. Information from grocery stores, Dairy Farmers of Canada or other production companies were perceived as marketing campaigns aimed at selling products, making this information untrustworthy.

Based on these findings, draft messages incorporated a series of 'myth busters', providing information pertaining to dairy products from sources that participants specified as trustworthy. In addition, information on the expected outcomes of consuming dairy products and ethical concerns included references to trusted sources' websites and summaries of research articles so that participants could examine this information themselves.

\section{Purchasing strategies}

Habitual

Parents of children who met the recommended intake of dairy discussed how purchasing dairy products was 
largely habit, part of their regular food shop, with one parent stating:

'I just have staples, butter, milk, cheese. Every shop we buy the staples.'

Parents of children meeting the recommended intake of dairy reported that purchasing decisions were often made based on ensuring products incorporated all food groups, as explained by one parent:

'And I'm going to make sure at the end of the day, he's had his protein, dairy and veggies and I'm happy. That's how we shop so, I don't know, I'm not always thinking of those things, that's just not how I shop or eat, really.'

Parents of children who failed to meet the recommended intake of dairy did not discuss habitual strategies.

\section{Bulk buy}

Dairy products were commonly bought in bulk by parents of children who consumed adequate dairy as a way of ensuring constant availability for consumption within the home. Bulk purchasing was also considered possible due to the ability of dairy products to be frozen, as one parent stated:

'We freeze a lot of cheese, I always shred it, because we have a lot of homemade pizza so I'll be like "Yay! Shredded cheese!" and then we'll make our little pizzas.'

Parents of children who did not meet the recommended intake of dairy did not discuss this strategy.

\section{Comparing costs}

All parents discussed comparing the cost of dairy products across different stores and making purchasing decisions based on which products were on sale. One parent highlighted the power of a sale in a comment:

'Print advertising I don't read. Any kind of advertising I think we're trained to just glance over it, unless there is a sale.'

\section{Product likeability}

All parents agreed that buying products that they knew their children liked, and would therefore consume, was an essential purchasing strategy, with one parent commenting:

'Looking at what's not being eaten, like I got just really weird flavoured yoghurt the last shop and no one has really eaten it. Just based on taste.'

\section{Reading labels}

In addition to purchasing products based on their children's taste preferences, mothers of children who failed to meet the recommended intake of dairy and all fathers discussed simultaneously reading food labels in an effort to buy fewer processed products:

'Yeah, when it says artificially flavoured I tend to just stay away from it.'

Furthermore, parents sought to purchase local products from smaller companies where possible:

'I avoid the big corporations because I don't trust them. And, um, I try to look for smaller companies that are more ethical.'

\section{Planned purchases}

All parents discussed the importance of planning dairy purchases. Planning occurred in a variety of ways, including: (i) meal planning; (ii) making a grocery list to guide shopping; (iii) selecting products from the perimeter of the grocery store; and (iv) selecting a grocery store based on products sold and pricing. As an example, one parent stated:

'We usually have a menu on my, like, very organized weeks.'

And another commented:

'I shop in a few spots. I do it all, like I do Costco, to health food stores, to farmers' market.'

Subsequent intervention messages included information on how to plan food purchases, identify healthy products in the grocery store and how to save money, for example through bulk buying products. All participants in the elaborative phase discussed that they would utilize these strategies themselves.

\section{Consumption strategies}

\section{Balance}

All parents expressed that they tried to ensure each meal was nutritionally balanced by ensuring each food group was present, rather than focusing specifically on dairy products, with one parent commenting:

'So, it's really about, to me, you go grocery shopping and you make sure your fridge is filled with the right portions of food, and then the rest will happen on its own.'

\section{Supplements}

Parents of children who did not meet the recommended intake of dairy discussed the use of dairy product supplements in their diets including almond milk, soya milk, broccoli and other greens, as well as tablet supplements. For example, one parent stated:

'For calcium and stuff, we get these raw green powders that we drink every morning, just to supplement for the calcium and vitamins, it has lots of good stuff in there.' 
Parents of children who met the recommended intake of dairy did not discuss the use of supplements as a consumption strategy.

\section{Creativity}

All mothers expressed that being creative with food regarding visual appearance and textures was important to ensure that children consumed a healthy diet. Concerning dairy consumption, one parent commented:

'We used these [small yoghurt packets] but I take the tops and we put our own yoghurt into them.'

\section{Availability and accessibility}

Ensuring dairy products are always available in the house in a manner that is convenient for children to eat by themselves or that can be eaten on the go is a consumption strategy utilized by all parents. As one parent commented:

'Yup, it's convenient. The yoghurt tube is the easiest way to get her yoghurt, because she doesn't waste any of it. There's no spoon, suck on the piece of plastic.'

\section{Autonomy}

Ensuring food is available and accessible to children was important for all mothers and fathers of children who met the recommended intake of dairy, to provide children with a feeling of autonomy. Providing autonomy was believed to lead to greater engagement with food, as noted by one parent:

'We had a little sectioned off part of the fridge, and that was "her" section. We had a glass of water in there, a glass of milk, and whatever ... She was excited because she felt independent.'

Providing children with autonomy also extended to enabling children to pick their choice of product at the grocery store to assist with consumption at home. All mothers and fathers of children who did not meet the recommended intake of dairy utilized autonomy as a consumption strategy for healthy food in general.

\section{Combining products}

Parents of children who consumed adequate dairy discussed many ways of combining dairy products with other foods to ensure consumption. The most popular combinations included milk in coffee (for parents only), cereal with milk, and using milk or cheese as a cooking ingredient. One mother explained how she combines dairy products for her child:

'Hiding it in a bit like that, in soups and things, in one-pot meals. That's where I try to get things that he's not necessarily crazy about. Like with smoothies.'

Parents of children who did not consume adequate dairy did not mention this strategy of combining products to bolster consumption.

\section{Role modelling}

All parents believed that role modelling was one of the most effective strategies to ensure their child consumed adequate dairy products and this belief subsequently served as a personal consumption strategy. One parent explained:

'I think that's how you develop being a child though, being a role model. You can feed them as healthy as you want but if they see you eat something else, then they're going to model that later in their life, so you have to eat healthy if you're expecting them to. There's probably more impact on them than you know.'

Intervention messages that incorporated these strategies were presented to participants in Phase II discussions. Participants reported that they utilized some of these strategies already and would try to adopt the strategies they were not currently using. It was clear that parents wanted additional strategies on how to incorporate more dairy products into meals at home and school and suggestions on how to involve children.

\section{Methods of communication}

Parents expressed a desire for information in two distinct formats. Specifically, parents wanted messages pertaining to consumption and purchasing strategies to be fun and interactive, with an emphasis on engaging their children. Catching the attention of their children meant that parents were more likely to pay attention, as one parent stated:

'That's a really effective way to make me listen is through my child, because it's something we can do together.'

Proposed methods of delivering this information included infographics, recipes that involved children, a calendar, and other novel activities to spike children's interest.

Simultaneously, parents sought information regarding the pros and cons of dairy products to be provided in a formal manner from trusted, unbiased sources, enabling them to make informed decisions. Preferred methods of delivery for this information varied between mothers and fathers. Fathers preferred short facts, while mothers sought more in-depth information in the form of an editorial. For example, one father stated:

'What's going to stick with me is short, quick facts.' 
Whereas one mother commented:

'I would read it and ingest it and probably, if I was getting it from a credible source and I didn't have to query it all the time ... that's the main way that I would be interested in this information.'

Parents believed that receiving this information in the form of a newsletter would be appropriate; however, there was some disagreement as to whether this should be sent via postal mail or electronically. Most parents concluded that mail newsletters were favourable as it enabled them to review the document at their leisure, while an email may be deleted without being read on busy days. Source credibility was of utmost importance for this information, with one parent stating:

'For me and probably my peer group, it just needs to be from a credible source.'

As soon as parents felt that the information was coming from organizations or individuals with a vested interest to sell products, their frame of reference shifted from information sharing to advertising and the information was deemed invaluable. Parents suggested the use of a logo to remind them of the source of the information throughout the intervention messages.

Parents in Phase II agreed on the two formats of information delivery. However, they believed that the information did not have to be mutually exclusive and that by combining these two formats in one 'bundle', engagement of both the parent and child would be greater.

\section{Final message development}

Final message content was developed around the key themes (identified within quotation marks in the following paragraphs of the present section) identified within the Phase I and II group interviews, feedback from draft messages presented in Phase II and in collaboration with two behaviour change experts and a registered dietitian (example message content is provided in Table 2).

The benefits emphasized within message content pertained predominantly to 'nutritional content' and 'positive health outcomes' associated with consumption of dairy in comparison to non-dairy products and supplemental products or tablets. The favourable 'taste' of dairy products was not included as this was perceived a personal preference and providing recipes that may be perceived as tasty was considered more influential on increasing dairy consumption. In addition, the benefit of 'convenience' was highlighted.

The identified barriers of 'negative health outcomes' and 'contamination concerns' were addressed via a series of phrases designed to contradict these beliefs, or myth busters. The myth busters included facts from sources all participants considered trustworthy and were designed to contradict negative perceptions. A registered dietitian verified the content of the myth buster phrases to ensure all information was scientifically accurate. To further address the concern of 'lack of trustworthy information', messages also included information on where to find trustworthy information sources, how to assess the quality of information and provided direct links to research articles.

The barriers of 'excess packaging/processing' and 'cost' were addressed through the provision of purchasing strategies such as 'buying products in bulk'. Messages also contained strategies to assist with 'planning purchases', 'reading nutrient labels' and 'reducing costs'. Strategies to promote child engagement with food and consumption of dairy included: (i) suggestions on how to make food easily 'accessible' to children; (ii) novel ideas to make food more attractive for consumption ('creativity'); and (iii) advice on how to involve children in planning and cooking to increase 'autonomy'.

Recipes were included to provide practical strategies on ways to 'combine' dairy products within meals and provide a 'balanced' diet. All recipes were appropriate for parents and children to make together and suggestions on which preparation activities were suitable for children were included. All recipes were tested and the nutritional value calculated using ESHA Food Processor SQL software (ESHA Research Inc., Salem, OR, USA). Messages highlighted importance of parental 'role modelling' and provided tips on how parents could increase their role modelling behaviour.

Overall, the message content emphasized salient benefits of dairy consumption, addressed key barriers and provided numerous practical strategies in the aim of promoting dairy product purchasing and consumption in parents and their children.

\section{Discussion}

The main purpose of the current two-phase formative research study was to explore parents' social cognitions in relation to dairy product consumption and purchasing in order to inform content for health promotion messages and to establish parents' preferred communication modality through which to disseminate this information. Perceived benefits of dairy product consumption were similar for both mothers and fathers of children who consumed both above and below the recommended intake of dairy. However, differences were observed in purchasing and consumption strategies utilized by parents of children who consumed adequate dairy and those who did not. Regarding preferred methods of communication, there were gender differences. Taking account of these differences, recommendations for message content and dissemination methods are provided for future public health campaign messages targeting parents as a means to modify children's dietary behaviours. 
Table 2 Examples of the final targeted messages aimed at increasing dairy consumption in parents of children aged 4-10 years

Benefits
Convenience

Overall health

Nutritional content/bone health

Barriers

Negative health outcomes

Weight control - parent

Physical sensitivities

Processed (packaging and content)

Environmental concerns

Cost (regular products and organic)

Lack of knowledge/trustworthy information

Purchasing strategies Bulk

Cost

\section{Example 1}

Having healthy foods readily available is important for busy families. Minimize stress by having simple snacks readily available, such as cheese sticks, apples and trail mix.

Example 2

Buy dairy products that suit your lifestyle. If you are always out, it might help to purchase single-serving dairy products in bulk, so that you always have a healthy snack to take with you. Yoghurt is available in small

containers and cheese can be purchased in single, wrapped portions. Alternatively, for those who have time, buy in bulk and then separate into single-serve portions and freeze for future use. This will help you save money in the long run.

Example 1

Recovery from Exercise: What does the body need?

Both children and adults need food/drinks that help them refuel, rehydrate and rebuild muscles that have been worked during exercise, sport and play.

Contrary to popular belief, your body does not need sports drinks (primarily sugar and water) after a workout, particularly if your workout is less than 90 minutes. You can refuel using non-processed foods and drinks just as easily. Milk contains the perfect balance of naturally occurring protein, vitamins and minerals to refuel and promote muscle growth after a workout. Milk also contains water, which ensures hydration. Milk is also cheaper than the majority of sports drinks.

\section{Example 1}

Did you know: Plant foods that contain calcium (e.g. spinach and broccoli) contain substances that bind to calcium, decreasing calcium absorption into the body. For example, cooked spinach contains $115 \mathrm{mg}$ calcium per serving (1/2 cup), but only approximately $6 \mathrm{mg}(5 \%)$ of calcium is absorbed. Compare this to the $101 \mathrm{mg}$ (32\%) of calcium that is absorbed from one serving of milk.

Example 2

\section{Get Your Protein}

Kids and adults both need protein. Adequate protein is essential for growth and maintenance of bones and muscles. We also need protein for tissues, hair and nails.

Dairy products are a great source of protein: one cup of milk contains $8 \mathrm{~g}$ of protein as well as nine essential nutrients, like folate, calcium and $\mathrm{B}_{12}$. So rest assured, when you provide your kids with their go-to drink it is filled with healthy goodness. And, while you're pouring, be a role model and fill a glass for yourself too! When they see you making healthy choices, they'll feel confident that they can do it too.

\section{Example 1}

MYTH: CONSUMING DAIRY PRODUCTS CAN LEAD TO WEIGHT GAIN. Weight gain occurs when we consume more calories than the body can burn. Multiple research studies have demonstrated that consuming three servings of low-fat dairy as part of a balanced diet actually helps with weight control.

Example 1

Did you know: There is no scientific research to support that dairy consumption causes an increase in the production of mucus or other cold-related symptoms.

Example 2

Did you know: The link between milk consumption and asthma in children has not been scientifically proven - in fact, emerging studies suggest regular-fat products may protect against asthma.

Example 1

Goodbye excess packaging! Purchase a reusable container and decorate it with your children. Fill this container with yoghurt or cut-up cheese purchased in larger quantities.

Example 1

Know the Facts: Organic $v$. Conventional Products

Products labelled as 'natural' are not required to have any special ingredients or health benefits. When it comes to milk, organic means that the cows consumed only feed grown without the use of chemicals. ALL dairy cows in Canada are free from growth hormones (such as rbST (recombinant bovine somatotropin)) and antibiotics. When a cow is receiving medication to treat an illness, the cow is not milked until a minimum of $60 \mathrm{~d}$ after it has returned to full health.

According to the Dietitians of Canada, there is not enough scientific evidence to conclude that organic food is more nutritious than non-organic food. Organic and non-organic dairy products alike are free of hormones and antibiotics. You can easily avoid hormones in your dairy products by purchasing dairy from farmers regulated in Canada.

Example 1

Organic does not mean healthier when it comes to dairy! Dietitians have reported that the nutritional content of organic and regular milk is virtually identical and question whether it is worth the extra cost for organic dairy produce.

\section{Example 1}

Sources you can trust. It is hard to determine what information you can trust. When searching for nutritional information seek out non-biased, evidence-based sources including information from published research studies and sources such as the Heart and Stroke Foundation and The Dietitians of Canada. Look for websites ending in .ca, .gov or .edu

Is it healthier to consume raw milk? Pasteurization has very little impact on the nutritional value of milk. Pasteurization means heating the milk to a temperature that kills off any potentially harmful bacteria.

\section{Example 1}

Buy in Bulk: Although buying in bulk costs more upfront, if you are going to use it, it will be cheaper. Also remember that many products can be bought in bulk and then frozen for future use. For example, buy a bulk size block of cheese, grate the cheese and then freeze in individual Ziploc bags in quantities than can serve as toppings for pizza night. This strategy also helps you avoid buying the 'pre' items (e.g. pre-cubed, pre-diced, presliced). Pre-packaged foods are often more processed and cost more. Avoid this cost and make it from scratch at home.

\section{Example 1}

Did you know: Many of the products found in 'Health Food' stores can also be found in your typical grocery store and often for a lower cost. 
Table 2 Continued

Likeability

Reading labels (content and origin)

Planning

Consumption strategies Balance

Supplements

Creativity/variety

Convenience (availability and accessibility)

Autonomy
Example 1

Include a treat. There's no getting around it ... children love sweets. Don't we all! Make it work for both of you by rethinking what and how much you give them. Pack a treat with substance, such as homemade banana muffins or rice square treats made with protein-packed nut replacement butter (like sunflower butter or soya butter) instead of marshmallows. If you prefer to pack more traditional sweets, simply rein in the size. They don't need ten miniature cookies; one or two will satisfy a sweet tooth and still leave them room to eat the rest of their lunch. Example 1

Understand Nutrition Labels: Trying to determine what is healthy and what is not is tricky. Here are some handy tips on reading labels:

1. Look at the serving size: Try to determine how many of those servings are in the product and then determine how many you would eat in one sitting.

2. Look at the calories: Calories tell you how much energy you get from one serving of a packaged food.

3. Look at the percent Daily Value (\% Daily Value): \% Daily Value is based on the recommended daily intake values of each nutrient. It puts nutrients on a scale from $0 \%$ to $100 \%$. This scale tells you if there is a little or a lot of a nutrient in one serving of a food.

4. Try to get more of these nutrients: Fibre, vitamin A, vitamin C, iron, and calcium

5. Try to get less of these nutrients: Sugar, trans fat, and sodium.

6. Choose items with less sugar and higher protein to help you feel fuller for longer - such as Greek yoghurt and nuts.

If you are feeling overwhelmed by all the nutritional information go back to basics: Buy products in their pure, natural form, such as milk, Greek yoghurt, locally made cheese and eggs.

Example 2

Be Aware: Low-fat products often have more sugar and sodium than regular-fat products. Make sure to read the labels and compare products when making healthy choices.

Example 1

List It: Try to make sure that you go to the grocery store armed with your grocery list. Discuss with your family what they would like to eat in the upcoming week and ensure you have the ingredients for these dishes on the list. Having a list will make you less tempted to buy unhealthy processed products in the store.

Example 1

Parents: Eating a balanced diet keeps you and your child energized, healthy, and makes you feel great! Involve your child by having them mark the days on the calendar, using the stickers provided, where he/she eats a balanced diet. Children between 4 and 8 years old: You should eat 2 servings of dairy and alternatives, 5 servings of fruit and veggies, 4 servings of grains, and 1 meat/alternatives a day. Children between 9 and 13: You should eat 3 servings of dairy and alternatives, 6 servings of fruit and vegetables, 6 servings of grains, and 1-2 servings of meat and alternatives.

What does a serving look like?

Photographs of:

$175 \mathrm{ml}$ yoghurt

1 cup of milk

1 cup of fresh vegetables

Slice of bread

$3 / 4$ cup cerea

$1 / 2$ cup pasta

$1 / 2$ cup fish and meat

2 eggs

2 tbsp peanut or nut butters

Example 1

MYTH: TAKING VITAMIN/MINERAL SUPPLEMENTS IS A GOOD REPLACEMENT FOR FOOD. SupplementS are meant to be an addition to your diet rather than a replacement. Generally, absorption of vitamins and minerals in the body is higher from food than from tablets. If you are consuming a balanced diet including all four food groups, then you likely do not need supplements at all.

Example 1

What about school lunches? Deciding what to pack for school lunches can be a challenge. For kids, boringlooking food likely means it won't be exciting enough to get eaten. To avoid this scenario, pack a lunch with a purpose. Keep the focus on fun and try to create meals that are fresh, healthy and cost-effective. Try to use some of the tips below:

1. Bump up the colour. Bright colours are the easiest way to increase the 'wow' factor in your child's lunch. It's fun, inviting and, better yet, nutritious when the colour comes from all-natural foods such as carrots, cucumbers, blueberries, cherry tomatoes and strawberries. Why not try making homemade fruit yoghurt? Buy plain Greek yoghurt and mix with different fruits to create a protein-rich snack your kids will love.

2. Have fun with shapes. Full sandwiches can seem daunting to kids. Use cookie cutters to pare down the size and add a little flair. Buy a range of cutters (you can get these at the dollar store). Fun shapes can also be created with fruit (such as thin sliced apples or melons) and cheese. Being creative will make the food more appealing and enticing for your child.

3. Offer variety. Try to pack at least three different types of food every day. The lunch box is a meal on a plate, so try to include complex carbs, dairy, and fruits and vegetables. Try a bento-style container with separated food compartments to allow kids to look - and pick - at everything all at once. These containers are also reusable and your child can decorate them as desired.

4. Choose easy-to-eat foods. When your child is at the lunch table socializing, eating is not a priority. Make eating simple for them by providing easy-to-eat foods that can be snacked on such as homemade yoghurt tubes (where are those Zipzicles?!), cheese cubes, or sugar snap peas and other vegetables that can be sliced into more manageable matchsticks.

\section{Example 1}

All Hands on Deck

We all love to be the boss of our own bodies - especially young ones! You can give kids some control by letting them be part of the meal decision process. Get them involved in baking, cooking, setting the table, choosing produce at the grocery store, and meal planning. This increases their appetite for consuming whatever is made, as well as increases their excitement for helping out in the kitchen.

Even little ones can help with dinner prep by washing produce, ripping and drying lettuce for salads, measuring out ingredients, setting the table, and choosing what they want to eat for dinner on family night! 
Combining products

Role model

BONUS: It's a great way to add family time to your day.

Example 2

Their choice: Corner off a section of the fridge and make it your child's 'drawer'. Load this section with a variety of healthy snacks and drink options. When your child is thirsty or hungry they will know that they can go to their area and choose whatever they would like. You will be confident that everything in their drawer is parent-

approved and healthy!

Example 1

Overnight Oats

Ingredients

1 ripe banana, mashed (the more ripe/spotty the better)

2 tablespoons chia seeds (optional)

$1 / 3$ cup rolled oats

$1 / 4$ tsp cinnamon

2/3 cup milk

1/3 cup water

For garnish: soaked almonds, pepita seeds, hemp hearts, cinnamon, toasted coconut, nut butter, spices

(cinnamon, ginger, allspice)

Prep time: 3 minutes, Cook time: 2 minutes, Yields: 1 bow

Nutritional Info (per serving)

Calories: 419 , Fat: $13 \mathrm{~g}$, Carbs: $66 \mathrm{~g}$, Protein: $14 \mathrm{~g}$

Nutrient (\% Daily Value): Fibre: $45 \%$, Vit B6: $42 \%$, Vit B12: $38 \%$, Calcium: $33 \%$

Preparation

1. The night before: In a medium bowl, mash the banana until smooth, then stir in the chia, oats, cinnamon, milk, and water until combined.

2. Cover and refrigerate overnight.

3. In the morning: Scoop the oat mixture into a medium pot. Increase heat to medium-high and bring to a simmer.

4. Reduce heat immediately to medium-low, and stir frequently until heated throughout and thickened.

5. Pour oats into bowl and add any toppings you wish.

Example 2

Create unique combinations. All of us eventually get tired of eating the same foods every day, and your kids are no different. To avoid afternoon meal burnout, think outside the lunch box and embrace atypical lunches. For

ideas, see some of our favourite combos below:

- Hummus and sugar snap peas

- Edamame salad with corn and tomatoes

- Apples or bananas with nut (or nut alternative) butter

- Greek yoghurt swirled with honey and served with preserves, granola or trail mix

- Nut (or nut alternative) butter wrapped in lettuce leaves or on celery with dried raisins or cranberries

- Cheese sticks and apple slices or multigrain crackers

- Dry cereal or air-popped popcorn

- Vegetable sticks with yoghurt Tzatziki dip

- Fruit in mashed cottage cheese or yoghurt

- Cold tofu with sesame oil and soya sauce to dip it in

- Homemade sushi (with only the stuff your kid likes to put in it!)

- Rice wraps with veggies and protein your kid likes

Example 1

Somebody is Watching You!

Your children look up to you. Research shows that children's food choices are based on what they see their parents eat. Modelling healthy eating sets up lifelong healthy eating patterns for your child. Young children in particular are watching you all the time - so it's important to role model what you want them to eat.

You can easily become a superhero by ensuring your little one sees you:

- Making a point of eating at each meal - especially breakfast

- Choosing wholesome, unprocessed foods to snack on instead of junk food

- Drinking water and milk instead of pop and fruit juice

- Eating foods from all food groups - milk, fruit, vegetables, whole grains, and lean meats, fish or alternatives

- Making meal time family time - try involving your child in making this very fast and simple recipe! Young children

love to help with the prepping, setting the table, and measuring things out.

BONUS: The more involved they are in making it, the more likely they are to eat it! how the nutritional content of dairy directly compared with non-dairy products. Given that parental knowledge has been linked to engagement in practices to promote Ca intake in children ${ }^{(15)}$ and to dairy intake in children ${ }^{(32)}$, it is important that messages contain an educational component to satisfy parents' desire for nutritional knowledge.

In addition to the positive physical outcomes associated with dairy consumption, parents perceived a number of negative physical outcomes. Specifically, excess gas, diarrhoea, mucus, eczema and low energy were believed to be associated with dairy consumption for their child and information about the physical health benefits of consuming dairy products, particularly for their child, and 
themselves. Some parents believed these physical sensitivities to dairy products could be due to contamination of dairy products with hormones and antibiotics. Contamination of dairy products was a common barrier theme for all parents and has been reported previously in adults ranging from 18 to $\geq 60$ years of age ${ }^{(25,33,34)}$. These findings are concerning for countries with strict hormone and antibiotic use regulations by dairy farmers, such as Canada. Participants in the elaborative phase were extremely receptive to 'myth buster' messages as a method of dispelling misinformed beliefs but stressed the importance of information coming from credible sources.

\section{Source credibility}

A lack of trustworthy information was one of the most frequently discussed barriers to dairy consumption for parents. This finding echoes those of Jung et al. in a study of Canadian adults ${ }^{(25)}$. In the current study, parents reported feeling overloaded with nutritional information, but felt that the majority of this information came from non-credible, untrustworthy sources. Information provided by grocery stores and production companies was deemed untrustworthy and purely for advertising purposes. Information disseminated from health-care professionals, schools and universities (i.e. organizations that did not stand to gain a profit from their dairy consumption) were deemed trustworthy. In a metaanalysis of health communication tactics, Keller and Lehmann ${ }^{(35)}$ concluded that messages from sources perceived as non-reputable were not as effective as messages from sources perceived as reputable. Future health promotion messages should clearly identify the source of the information content to provide transparency and promote trust among readers.

\section{Tips on reducing costs}

A barrier specific to mothers was the cost of dairy products. It is possible that mothers are more aware of the cost of food products as they traditionally do the majority of the grocery shopping and meal preparation in the household ${ }^{(36)}$. The cost barrier was accentuated due to the belief that they should purchase organic dairy products for their children. Health promotion messages should provide evidence-based information on the health benefits of organic $v$. non-organic dairy products to enable parents to make informed decisions about purchasing organic products. Parents in the elaborative phase reported that this information was extremely informative and useful.

Not surprisingly, cost was identified as an important purchasing consideration, with all parents making purchasing decisions based on product sales. This purchasing strategy appeared to take precedent over other purchasing considerations. One purchasing strategy that was utilized by parents of children who consumed adequate dairy, and which would help to address cost concerns, was buying dairy products in bulk. Parents reported buying dairy in bulk and freezing products for consumption at a later date and to avoid spoiling. Given the importance of price for purchasing and consumption behaviours, future messages should contain practical strategies that can reduce groceryshopping costs.

\section{Provision of practical consumption strategies}

Regarding consumption, parents of children who consumed adequate dairy discussed combining dairy products with other food items to promote consumption for themselves and their child. Mothers in particular discussed that being creative with how food was presented was a useful strategy to ensure their children consumed a healthy diet. Consumption strategies utilized by all parents included making sure dairy products were available in the home and that these products were accessible for children to consume by themselves. This strategy provided children with a sense of autonomy that parents felt was important to promote dairy consumption. Despite the number of consumption strategies identified, all parents expressed a desire for additional practical tips and techniques to promote dairy consumption such as recipes, how to make lunch-box meals appealing and ways of increasing child engagement in food and eating. As such, it is important that future health promotion messages incorporate these 'hands-on' suggestions in order to increase parents' confidence to engage their children in food choices and to prepare meals containing dairy products so as to promote familial consumption.

\section{The power of role modelling}

Role modelling was identified as an effective consumption strategy for both parents and children. Parents were aware of the impact that their consumption behaviour had on their children's consumption and this relationship was extremely important to them. The value of role modelling reported in the current study is in line with previous research which revealed that acting as a role model was exceptionally important to parents in order to ensure their children engaged in healthy behaviours, often making up for a lack of concern regarding their personal eating habits ${ }^{(37)}$. Given that role modelling of healthy eating is essential in the development of long-lasting healthy nutrition behaviour in children ${ }^{(38)}$, health promotion messages should emphasize the importance of role modelling and provide suggestions on how to be a good role model.

\section{Clarity on supplementation}

Interestingly, parents of children who did not consume the recommended intake of dairy reported using supplements as a means of ensuring consumption of nutrients found within dairy products. Parents reported supplementing their diets and those of their children. It is important that 
parents are provided with evidence-based information related to pros and cons of supplementation $v$. dairy product consumption, as the nutritional profile of supplemental products will likely be different from that of dairy products. Furthermore, scientific concerns regarding the use of Ca-fortified foods and beverages have previously been highlighted ${ }^{(2)}$.

\section{Channels of communication}

With regard to knowledge dissemination methods, parents expressed a desire for: (i) fun and interactive materials that engaged their children, such as recipe books and calendars; and (ii) material that was adult-focused and provided factual information. Parents reported a preference for receiving this information in print rather than via email, with fathers expressing a desire for quick, easy-to-read facts and mothers seeking a more comprehensive article. Similarly, Birkett et $a l .{ }^{(39)}$ reported that parents had a preference for print materials in regard to nutrition education. Most importantly, information must come from a reputable, trustworthy source, such as a university or health-care provider, for the message content to be read and subsequently processed. If future public health campaigns fail to address this concern, the content of health messages will be irrelevant.

\section{Study limitations and strengths}

One limitation of conducted in-depth group interviews is that the findings may not be generalizable to the wider target population. Specifically, in the current study participants reported a high level of education, with $60 \%$ holding a university certificate or higher. Parents with lower education levels may hold different perceptions regarding the benefits and barriers to dairy product consumption as well as different purchasing and consumption strategies. As such, future research should be conducted with parents of children with differing education levels and socioeconomic status, to examine if differences do occur and to examine how these impact potential intervention messages. An inherent limitation of in-depth group interviews is that individuals may feel uncomfortable sharing their personal beliefs and may conform to the consensus of the group $^{(40)}$. To minimize these potential effects, all interviews were moderated by a researcher experienced in group moderation. The moderator began each session by informing participants that there were no right or wrong answers and that all thoughts and comments were valuable to the research. The moderator also asked participants if they had any different thoughts or feelings from those expressed by others in the group to help promote openness. In addition, interviews were coded by two raters, who displayed high inter-rater reliability. One of the strengths of the current research was the use of both exploratory and elaborative phases with two different groups of parents. The exploratory phase allowed for the examination of barriers to and benefits of purchasing and consuming dairy products, and identification of appropriate avenues of communication through which to share these messages. In the elaborative phase, social cognitions were further examined in order to confirm the findings revealed in Phase I and draft intervention messages and dissemination methods were presented to a new sample of the target audience. Directly involving the target audience in the development of health promotion messages is critical to the acceptance and success of an intervention ${ }^{(41)}$.

The present study draws on the extensive value parents attach to the health of their child to in turn create a series of messages directly targeting parents in an effort to promote positive behaviour change in both parent and child. Given the high rates of dairy underconsumption among young Canadian children, these findings have implications for public health initiatives. Specifically, future public health campaigns should ensure that nutritional information, particularly dairy, is imparted to parents from reputable sources such as their child's school or Health Canada. In addition, messages should endeavour to address the commonly held negative perceptions of dairy products, while highlighting the benefits their child could stand to gain. Public health campaigns should also provide a plethora of strategies to help parents feel confident to engage in the desired behaviour within their own home.

Future research should aim to examine the effectiveness of these intervention messages, targeted specifically towards parents as the 'nutritional gatekeepers', on increasing parent dairy-related behaviour and the consumption of dairy products by children.

\section{Acknowledgements}

Acknowledgements: The authors would like to thank Lindsay Burton for assistance with transcribing and coding the transcripts. Financial support: This work was supported by a grant from the Canadian Agri-Science Clusters Initiative, Dairy Research Cluster (Dairy Farmers of Canada, Agriculture and Agri-Food Canada, and Canadian Dairy Commission). The Canadian Agri-Science Clusters Initiative had no role in the design, analysis or writing of this article. Conflict of interest: None. Authorship: M.E.J. was responsible for project conception. M.E.J. and J.E.B. designed the research, developed the overall research plan, conducted the research, analysed the data, determined the content of the manuscript and collaborated on the writing. K.A.M.G. and A.B. contributed to the overall research plan and assisted with manuscript writing. All authors read and approved the final manuscript. Ethics of buman subject participation: This study was conducted according to the guidelines laid down in the Declaration of Helsinki and all procedures involving human subjects were approved by the University of British Columbia Behavioural Ethics Committee. Written informed consent was obtained from all subjects. 


\section{Supplementary material}

To view supplementary material for this article, please visit https://doi.org/10.1017/S1368980017002038

\section{References}

1. Dror DK \& Allen LH (2013) Dairy product intake in children and adolescents in developed countries: trends, nutritional contribution, and a review of association with health outcomes. Nutr Rev 72, 68-81.

2. Nicklas TA (2003) Calcium intake trends and health consequences from childhood through adulthood. $\mathrm{J} \mathrm{Am}$ Coll Nutr 22, 340-356.

3. Heaney RP (2009) Dairy and bone health. J Am Coll Nutr 28, Suppl. 1, 82S-90S.

4. Kalkwarf HJ, Khoury JC \& Lanphear BR (2003) Milk intake during childhood and adolescent, adult bone density, and osteoporotic fractures in US women. Am J Clin Nutr 77, 257-265.

5. Huth PJ, DiRienzo DB \& Miller GD (2006) Major scientific advances with dairy foods in nutrition and health. J Dairy Sci 89, 1207-1221.

6. Health Canada, Statistics Canada (2009) Canadian Community Health Survey, Cycle 2.2, Nutrition (2004). Nutrient Intakes from Food: Provincial, Regional and National Data Tables Volumes 1, 2 \& 3 Disk. Ottawa: Health Canada Publications.

7. Health Canada (2011) Eating well with Canada's food guide - a resource for educators and communicators. https://www. canada.ca/en/health-canada/services/food-nutrition/reportspublications/eating-well-canada-food-guide-resource-educatorscommunicators-2007.html (accessed February 2015).

8. Quann EE, Fulgoni VL 3rd \& Auestad N (2015) Consuming the daily recommended amounts of dairy products would reduce the prevalence of inadequate micronutrient intakes in the United States: diet modelling study based on NHANES 2007-2010. J Nutr 14, 90.

9. Baird DL, Syrette J, Hendrie GA et al. (2012) Dairy food intake of Australian children and adolescents 2-16 years of age: 2007 Australian National Children's Nutrition and Physical Activity Survey. Public Health Nutr 15, 2060-2073.

10. Hendrie GA, Brindal E, Baird D et al. (2013) Improving children's dairy food and calcium intake: can intervention work? A systematic review of the literature. Public Health Nutr 16, 365-376.

11. Wansink B (2006) Nutritional gatekeepers and the $72 \%$ solution. J Am Diet Assoc 106, 1324-1327.

12. Cooke LJ, Wardle J, Gibson EL et al. (2003) Demographic, familial and trait predictors of fruit and vegetable consumption by pre-school children. Public Health Nutr 7, 295-302.

13. Fisher JO, Mitchell DC, Smiciklas-Wright H et al. (2004) Meeting calcium recommendations during middle childhood reflects mother-daughter beverage choices and predicts bone mineral status. Am J Clin Nutr 79, 698-706.

14. Scaglioni S, Salvioni M \& Galimberti C (2008) Influence of parental attitudes in the development of children eating behaviour. Br J Nutr 99, Suppl. 1, S22-S25.

15. Cluskey M, Edlefsen M, Olson B et al. (2008) At home and away-from-home eating patterns influencing preadolescents' intake of calcium-rich foods as perceived by Asian, Hispanic and non-Hispanic White parents. J Nutr Educ Behav 40, 72-79.

16. Evans CEL, Greenwood DC, Thomas JD et al. (2010) SMART lunch box intervention to improve the food and nutrient content of children's packed lunches: UK wide cluster randomised controlled trial. J Epidemiol Community Health 64, 970-976.

17. Van Horn L, Obarzanek E, Friedman LA et al. (2005) Children's adaptations to a fat-reduced diet: the Dietary Intervention Study in Children (DISC). Pediatrics 115, 1723-1733.

18. Epstein LH, Paluch RA, Beecher MD et al. (2008) Increasing healthy eating vs. reducing high energy-dense foods to treat pediatric obesity. Obesity (Silver Spring) 16, 318-326.

19. Haire-Joshu D, Elliott MB, Caito NM et al. (2008) High 5 for Kids: the impact of a home visiting program on fruit and vegetable intake of parents and their preschool children. Prev Med 47, 77-82.

20. Lien N, Lytle LA \& Klepp KI (2001) Stability in consumption of fruit, vegetables and sugary foods in a cohort from age 14 to age 21. Prev Med 33, 217-226.

21. Lytle LA, Seifert S, Greenstein J et al. (2000) How do children's eating patterns and food choices change over time? Results from a cohort study. Am J Health Promot 14 , 222-228.

22. Bandura A (1986) Social Foundations of Thought and Action: A Social Cognitive Theory. Englewood Cliffs, NJ: Prentice-Hall, Inc.

23. Jung ME, Martin Ginis KA, Phillips SM et al. (2011) Increasing calcium intake in young women through gain-framed, targeted messages: a randomised controlled trial. Psychol Health 26, 531-547.

24. Jung ME, Latimer-Cheung AE, Bourne JE et al. (2016) Targeted messages increase dairy consumption in adults: a randomized controlled trial. Ann Behav Med 51, 57-66.

25. Jung ME, Mistry C, Bourne JE et al. (2015) A qualitative investigation of adults' perceived benefits, barriers and strategies for consuming milk and milk products. Health Educ J 74, 364-378.

26. Ong JX, Ullah S, Magarey A et al. (2016) Positive influences of home food environment on primary-school children's diet and weight status: a structural equation model approach. Public Health Nutr 19, 2525-2534.

27. Pearson N, Biddle SJ \& Gorely T (2009) Family correlates of fruit and vegetable consumption in children and adolescents: a systematic review. Public Health Nutr 12, 267-283.

28. Moore LL, Bradlee ML, Gao D et al. (2008) Effects of average childhood dairy intake on adolescent bone health. J Pediatr 153, 667-673.

29. Sparkes A \& Smith B (2013) Qualitative Research Methods in Sport, Exercise and Health Sciences: From Process to Product. London: Routledge.

30. British Columbia Dairy Foundation (2008) Calcium Calculator. https://bcdairy.ca/nutritioneducation/calcium calculator (accessed February 2015).

31. Hung A, Hamidi M, Riazantseva E et al. (2011) Validation of a calcium assessment tool in postmenopausal Canadian women. Maturitas 69, 168-172.

32. Brett NR, Vanstone CA, Maguire JL et al. (2016) Parental knowledge, perceptions and consumption of milk and alternatives relates to intakes of young children 2-8 y of age. FASEB J 30, Suppl. 295.3.

33. Marcinow ML, Randall Simpson JA, Whiting SJ et al. (2017) Young adults' perceptions of calcium intake and health: a qualitative study. Health Educ Behav (Epublication ahead of print version).

34. Mobley AR, Jensen JD \& Maulding MK (2014) Attitudes, beliefs, and barriers related to milk consumption in older, low-income women. J Nutr Educ Behav 46, 554-559.

35. Keller PA \& Lehmann DR (2008) Designing effective health communications: a meta-analysis. J Public Policy Mark 27, $117-130$ 
36. Private Label Manufacturers Association (2013) Today's Primary Shopper. PLMA Consumer Research Study, New York. http://plma.com/2013PLMA_GfK_Study.pdf (accessed September 2016).

37. Aschemann-Witzel J (2013) Danish mothers' perception of the healthiness of their dietary behaviors during transition to parenthood. J Fam Issues 34, 1335-1355.

38. Golan M \& Crow S (2004) Parents are key players in the prevention and treatment of weight-related problems. Nutr Rev 62, 39-50.
39. Birkett D, Johnson D, Thompson JR et al. (2004) Reaching low-income families: focus group results provide direction for a behavioral approach to WIC services. J Am Diet Assoc 104, 1277-1280.

40. Krueger RA \& Casey M (2009) Focus Group: A Practical Guide for Applied Research, 4th ed. Thousand Oaks, CA: SAGE Publications, Inc.

41. Glanz K, Rimer BK \& Lewis FM (2002) Health Behavior and Health Education: Theory, Research, and Practice, 3rd ed. San Francisco, CA: Jossey-Bass. 